\section{$\underset{\substack{\text { hommes } \\ \text { \& migrations }}}{ }$}

\section{Hommes \& migrations}

Revue française de référence sur les dynamiques

migratoires

$1282 \mid 2009$

Santé et droits des étrangers : réalités et enjeux

\title{
Christophe Carrère, Leconte de Lisle ou la passion du
}

beau

Éditions Fayard, 2009, 677 pages, 34 euros

\section{Mustapha Harzoune}

\section{CpenEdition}

Journals

Édition électronique

URL : http://journals.openedition.org/hommesmigrations/482

DOI : 10.4000/hommesmigrations.482

ISSN : 2262-3353

Éditeur

Musée national de l'histoire de l'immigration

Édition imprimée

Date de publication : 1 novembre 2009

Pagination : 206-207

ISSN : 1142-852X

Référence électronique

Mustapha Harzoune, "Christophe Carrère, Leconte de Lisle ou la passion du beau », Hommes \& migrations [En ligne], 1282 | 2009, mis en ligne le 29 mai 2013, consulté le 22 septembre 2020. URL: http://journals.openedition.org/hommesmigrations/482 ; DOl : https://doi.org/10.4000/

hommesmigrations.482

Ce document a été généré automatiquement le 22 septembre 2020.

Tous droits réservés 


\title{
Christophe Carrère, Leconte de Lisle ou la passion du beau
}

Éditions Fayard, 2009, 677 pages, 34 euros

\author{
Mustapha Harzoune
}

\section{RÉFÉRENCE}

Christophe Carrère, Leconte de Lisle ou la passion du beau, Editions Fayard, 2009, 677

pages, 34 euros

1 Cette biographie, pointue et méticuleuse, que Christophe Carrère consacre à celui que nos vieux manuels affublent du triste titre de "prince des Impassibles", dépoussière heureusement nos représentations sur l'homme et son œuvre. À bien des égards et $a$ contrario de l'officielle caricature, ce Charles Leconte de Lisle, né un 22 octobre de l'année 1818 et mort le 17 juillet 1894, apparaît comme un être fragile et amoureux, à commencer de sa cousine, Marie-Elixène de Lanux, partie si jeune et qui toujours restera sa muse. Un homme souvent sympathique, clairvoyant et même drôle. Dans son œuvre - Poèmes antiques (1852), Poèmes barbares (1862) et Poèmes tragiques (1884) ${ }^{1}$ voisinent le polythéisme grec puis hindouiste, son île de La Réunion, la nature et la faune, les soubresauts et les bassesses d'un siècle où l'argent devient roi, les flèches tirées sur les tartuffes et autres bondieuseries. Leconte de Lisle se révèle à la fois d'une actualité étonnante et d'une exigence qui, elle, semble appartenir à un autre temps.

Christophe Carrère écrit que Leconte de Lisle est "un être métissé, morcelé, fragmenté, brisé, un poète immigré, moderne parce que bigarré, pluraliste et nomade, à dimension universelle". Il veut en finir avec "la légende, pourtant combattue depuis les origines par les amis du poète et par le poète lui-même, de l'impassibilité élitiste, de la condescendance olympienne".

3 Cet être fragmenté a passé son enfance et une partie de sa jeunesse entre l'île Bourbon natale, l'actuelle Réunion, et la Bretagne, du côté de Rennes (Dinan) avant de s'installer 
à Paris en 1845. Fils de colon, il s'engagera pourtant aux côtés de Victor Schoelcher contre l'esclavagisme.

4 Anticlérical, il fustige "les paradoxes de cette orthodoxie (catholique) qu'il avait vue s'épanouir dans la vie culturelle des créoles de Bourbon, et notamment chez sa mère, catholique fervente, qui ne s'était jamais attendrie du sort des esclaves aux oreilles coupées, aux mains tranchées, aux jarrets sectionnés [...]".

5 Très tôt, le jeune Charles crut en sa vocation poétique, mais c'est bien tard que le vieillissant Leconte de Lisle reçu quelques lauriers. Le chef de file des Parnassiens comptera pour principaux disciples le fidèle Hérédia, Villiers de l'Isle-Adam, Léon Dierx, Sully Prudhomme et Mallarmé. Il fut reconnu par ses pairs - y compris par ceux qui, comme France, Verlaine, Mallarmé ou Baudelaire, s'en écartèrent - comme l'un des plus grands poètes de sa génération. Pourtant, une longue partie de sa vie, il eut à se débattre contre une angoissante et tenace pauvreté. L'Empire lui accorda bien une pension et le décora même. Mais, outre que cela lui fut reproché à la chute du "petit" Napoléon, ces maigres subsides ne lui permirent pas de vivre à l'aise et de subvenir aux besoins des siens. La République le fit sous-bibliothécaire au Sénat et le nomma officier de la Légion d'honneur. En 1886, après s'être enfin résolu, plié, aux protocolaires visites, Leconte de Lisle fut élu à l'Académie française, au fauteuil quatorze, celui de Victor Hugo.

Pourtant perspicace, la politique ne fut pas son fort. Fouriériste à ses débuts, il délaissa ses premiers engagements pour un socialisme bon teint et une fibre républicaine. Il finira même par s'insurger contre le dogme fouriériste "pour s'orienter vers la route claire de la pure et simple beauté". Car cet homme épris d'idéal et de hauteur fut déçu. "Il fallait renoncer à la politique qui [...] n'était pas faite pour les poètes." Les masses sont stupides comme les politiciens. Il deviendra même un anticommunard que Verlaine cessera de fréquenter pour cette raison.

7 Pour son biographe, "loin de le blâmer d'être entré - si peu - dans l'arène politique, il convient donc de le féliciter d'en être si vite ressorti. De fait, sa supériorité sur Ménard vient de la rapidité avec laquelle il a choisi l'échec [...]. Leconte de Lisle ne subit pas l'échec à la manière de Flaubert: il le prend pour thème poétique et comme conversion à l'Idéal." C'est ainsi qu'il va peu à peu, explique Christophe Carrère, "ne s'attacher qu'à la seule beauté qui fut à la fois moralement unique et esthétiquement multiple, celle de la forme".

8 Voici donc une biographie pointue, où l'intimité du poète voisine avec les fracas de ce bruyant XIX ${ }^{e}$ siècle. L'un des nombreux intérêts de ce travail est de ne pas chercher à masquer les contradictions, les évolutions, l'absence de logique de système chez cet esprit rétif à toutes représentations figées qui, pour autant, ne galvauda jamais certains principes et ne prostitua aucune de ses valeurs.

"L'homme que j'étais n'aura jamais été connu", disait Leconte de Lisle de lui-même. Suivons pourtant Christophe Carrère dans sa tentative de lever le voile sur la double nature $\mathrm{du}$ poète, celle du "paria, proscrit des lettres françaises et de personnage créole tourmenté entre deux natures, la blanche et la noire, la libre et l'asservie, la républicaine et l'aristocratique, la parisienne et la saint-pauloise, la très secrète et la plus célèbre. Si Charles revêtait un masque, Leconte de Lisle, lui, en affichait bien mille". 


\section{NOTES}

1. Tous disponibles en poche chez Gallimard dans la collection Poésie. 